\title{
Cytodifferentiation of Photoreceptors in Larval Goldfish: Delayed Maturation of Rods
}

\author{
PAMELA A. RAYMOND \\ Department of Anatomy and Cell Biology, The University of Michigan Medical School, \\ Ann Arbor, Michigan 48109-0010
}

\begin{abstract}
This study describes the differentiation of photoreceptors in larval goldfish retina. The earliest photoreceptors to differentiate were cones; ${ }^{3} \mathrm{H}$-fucose labeled cone but not rod outer segments in larval as well as adult goldfish. All major cone types known to be present in the adult goldfish retina (double cones, long and short single cones) were found in the larval retina by 2 days after hatching. The cones matured rapidly; within a few days they had welldeveloped outer segments and synaptic pedicles that were smaller, but otherwise similar to those in adults. Rods were slower to mature. Their outer segments were at first short, wide, and misshapen; only as they grew longer and narrower did they become straight and properly aligned. Rod spherules were first seen in fish older than 1 month; immature rods contained perinuclear synaptic ribbons and invaginating processes penetrated the cell body. These results suggest that the influence of rods and cones on visual function in larval goldfish may be quite different from the adult.
\end{abstract}

Key words: retinal development, cone pedicle, rod spherule, $3 \mathrm{H}$-fucose autoradiography, retinal ultrastructure

The cytoarchitecture of the larval goldfish retina differs substantially from that of adults, especially in the outer layers (Johns, '82). The most obvious difference is that the photoreceptor layer is much thinner in larvae than in adults. At hatching, the outer nuclear layer is represented by a single row of cells (Johns, '82), whereas in the adult, the outer nuclear layer consists of four or more rows of nuclei: one row of cones and three or more rows of rods (Stell and Hárosi, '76; Johns and Easter, '77). The single row of nuclei present at hatching appear to differentiate into cones, whereas all rod nuclei are added to the outer nuclear layer postembryonically, after stratification of the retina is complete and the surrounding neurons have become postmitotic (Johns, '82). Recent studies with thymidine autoradiography have shown that rods in larval goldfish, and in several other teleost species, are derived from a special population of dividing precursor cells located in the outer nuclear layer (Sandy and Blaxter, '80; Johns, '82; Raymond and Rivlin, '84). The capacity for mitotic activity persists in rod precursors, so that new rods continue to be generated and inserted into the photoreceptor mosaic even in adult fish (Johns and Fernald, '81).
Previous work on the formation and development of photoreceptors in teleost fish has relied mainly on light microscopy (Müller, '52; Lyall, '57a,b; Wagner, '74). In an earlier study of larval goldfish, immature rod outer segments (ROS) were first identified at 2-3 days after hatching (Johns, '82). At aboult the same time, a second row of nuclei, presumed to be rods, appeared in the outer nuclear layer vitread to the cone nuclei. However, some of the nuclei in the outer nuclear layer could be labeled with ${ }^{3} \mathrm{H}$-thymidine, suggesting that they were dividing rod precursors, even though they could not be distinguished histologically from postmitotic rod nuclei. In addition, it was not easy to discriminate in the young larvae the various classes of cones known to be present in the mature goldfish retina-double cones, long single cones, short single cones, and a few miniature types (Stell and Hárosi, '76; Marc and Sperling, '76). The present study was undertaken to clarify and amplify results from the earlier work. Electron microscopy and the selective

Accepted February 6, 1985

P.A. Raymond published previously under the name P.R. Johns. 
label ${ }^{3} \mathrm{H}$-fucose, which is incorporated into cone outer segments (COS) but not ROS in the adult goldfish retina (Bunt and Klock, '80a), were used to identify and characterize developing photoreceptors.

The results corroborate previous studies and allow a more precise temporal description of cytodifferentiation of photoreceptors. The major conclusions are that all postmitotic nuclei in the photoreceptor layer at hatching are cones, and all major cone types are present in the larval retina. Electron microscopic observations suggest that a few ROS have begun to develop in central retina as early as 1 day after hatching, rather than at 2 or 3 days as suggested by light microscopy. Finally, the time course and sequence of maturation of rods and cones differs: cones as a rule increase in size systematically in most dimensions throughout larval and adult life; ROS also increase in length up to a certain point and then shorten, but while they are elongating they also become narrower. Some of these results have been reported in a preliminary communication (Johns and Holcombe, ' 82 ).

\section{METHODS \\ Breeding and rearing goldfish in the laboratory}

Sexually mature, gravid goldfish weighing between 100 and $200 \mathrm{~g}$ were obtained from a commercial supplier (Ozark Fisheries, Stoutland, MO) a few months prior to the normal breeding season, which typically begins in April or May. They were maintained in aerated artificial pond water (Allee et al., '40) at $18-21^{\circ} \mathrm{C}$ and fed ad libitum six times per week with Purina Trout Chow supplemented once or twice weekly with live redworms (Carolina Biological Supply). Spawning was induced hormonally. A gravid female was injected intramuscularly between 4 and 5 P.M. with carp pituitary extract (Hydro-Quest International, Rosemont, NJ), 1-10 mg dissolved in sterile water or in sterile physiological $(0.9 \%)$ saline. The female and a male were placed together in a 20 -gallon aerated aquarium containing floating aquatic plants with water temperature at $22-24^{\circ} \mathrm{C}$. Embryos were collected the next morning.

Under the standard laboratory conditions described above, goldfish could be successfully bred from late winter to midsummer, but to maintain fish in a state of reproductive maturity throughout the year, special conditions were required. Males and females were separated by a screened partition in a 75-gallon refrigerated tank (Frigid Units, Toledo, $\mathrm{OH}$ ). Water temperature was maintained at $15^{\circ} \mathrm{C}$ under cyclic fluorescent illumination (GE F40D, daylight bulbs; 10 hours on/14 hours off). Protocols for feeding and spawning were as described above, except that sometimes the male was also injected with pituitary extract.

Embryos were hatched in either artifical pond water (Allee et al., ' 40 ) with $0.1 \mathrm{mg}$ methylene blue $/ 100 \mathrm{ml}$ added to inhibit fungal growth, or teleost embryo-rearing solution (Rugh, '62), which also contained $0.1 \mathrm{mg}$ methylene blue/ $100 \mathrm{ml}$. The highest survival rates were obtained when embryos were hatched in open $9-\times 12-\times 4$-inch trays with constant aeration at $18-20^{\circ} \mathrm{C}$. Dead embryos, which became opaque and stained blue by the dye, were removed from the trays daily. The day of hatching was designated as day 0 . This method of staging animals was admittedly somewhat arbitrary since hatching among fish from a single spawn occurred over a period of 3 days or longer. In general, however, the more precocious animals were more vigorous and were selected for study. Larvae began eating at about 3 days; they were fed live nauplii of brine shrimp
(Artemia, San Francisco Bay Co.). Larval development in goldfish lasts about 3 weeks (Kajishima, '60), but the transition from larval to juvenile stages is very gradual and uneventful in terms of retinal development (Johns, '82).

\section{Autoradiography}

Larval fish, 0-14 days after hatching, were lightly anesthetized in $0.02 \%$ tricaine methane sulfonate (Sigma) and then injected intraperitoneally with approximately $1 \mu \mathrm{Ci}$ of ${ }^{3} \mathrm{H}$-fucose (56 Ci/mmol, New England Nuclear, Boston, MA) in $0.05 \mu \mathrm{l}$ of $0.9 \% \mathrm{NaCl}$ using a micropipet (Johns, '82). Survival periods ranged from 4 hours to 9 days. Tissues were processed for light or electron microscopy as described below.

Two juvenile goldfish, 6 months old, 3.3 and $3.4 \mathrm{~cm}$ standard body length (which excludes the tail), were anesthetized in tricaine methane sulfonate $(0.2 \%)$ and injected intraocularly with $10 \mu \mathrm{Ci}{ }^{3} \mathrm{H}$-fucose in $0.5 \mu \mathrm{l}$ sterile saline. Fortyeight hours later, they were killed and the eyes were processed for light microscopic autoradiography as described below.

\section{Light microscopy}

Larvae were fixed whole in $1 \%$ paraformaldehyde, $2 \%$ glutaraldehyde and $0.1 \%$ picric acid in $0.1 \mathrm{M}$ phosphate buffer (ph 7.2) overnight at $5^{\circ} \mathrm{C}$. For larger fish the eyes were first removed, the cornea and lens were dissected away, and the eyecups were fixed as described. Tissues were rinsed in buffer, dehydrated to $95 \%$ ethanol, and embedded in Sorvall Embedding Medium (Dupont). Frontal sections, $3 \mu \mathrm{m}$ thick, were processed for autoradiography (when appropriate) and stained with Lee's methylene blue/ basic fuchsin (Johns, '82).

\section{Electron microscopy}

Larvae were fixed whole in $3 \%$ glutaraldehyde, $3 \%$ paraformaldehyde, and $5 \%$ sucrose in $0.1 \mathrm{M}$ sodium cacodylate,

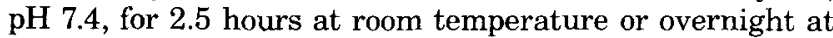
$4^{\circ} \mathrm{C}$. Tissues were rinsed in the same buffer with $5 \%$ sucrose and then postfixed for 1.5 hours at room temperature in a freshly-made mixture of $1 \%$ osmium tetroxide and $1 \%$ potassium ferricyanide (Langford and Coggeshall, '81). En bloc staining with uranyl acetate was followed by embedding Spurr's medium (Polysciences). Only the central twothirds to three-fourths of each retina was studied. The numbers of retinas examined in the electron microscope at each age were as follows: 0 days, three; 1 day, three; 2 days, one; 3 days, one; 5 days, one; 6 days, one; 10 days, one; 2 weeks, one; 1 month, one; 3 months, one; 8 months, two.

Thin sections were processed for autoradiography using a modified flat substrate method (Davis et al., '79) with Ilford L-4 Nuclear Emulsion (Polysciences). A dipping machine (Rogers, '79) was used to ensure consistency of the emulsion coating. Slides were exposed at $4^{\circ} \mathrm{C}$ for up to 6 months and developed in D-19. Excess emulsion was removed with 0.1 $\mathrm{N} \mathrm{NaOH}$, and sections were stained with uranyl acetate and lead citrate and were viewed in a Philips 400 electron microscope.

\section{Morphometry}

Retinas from 20 eyes were examined from fish ranging in age from hatching to about 4 years old. Animals less than 3 months of age were reared in the laboratory and older ones were purchased from Ozark Fisheries. Dimensions of 

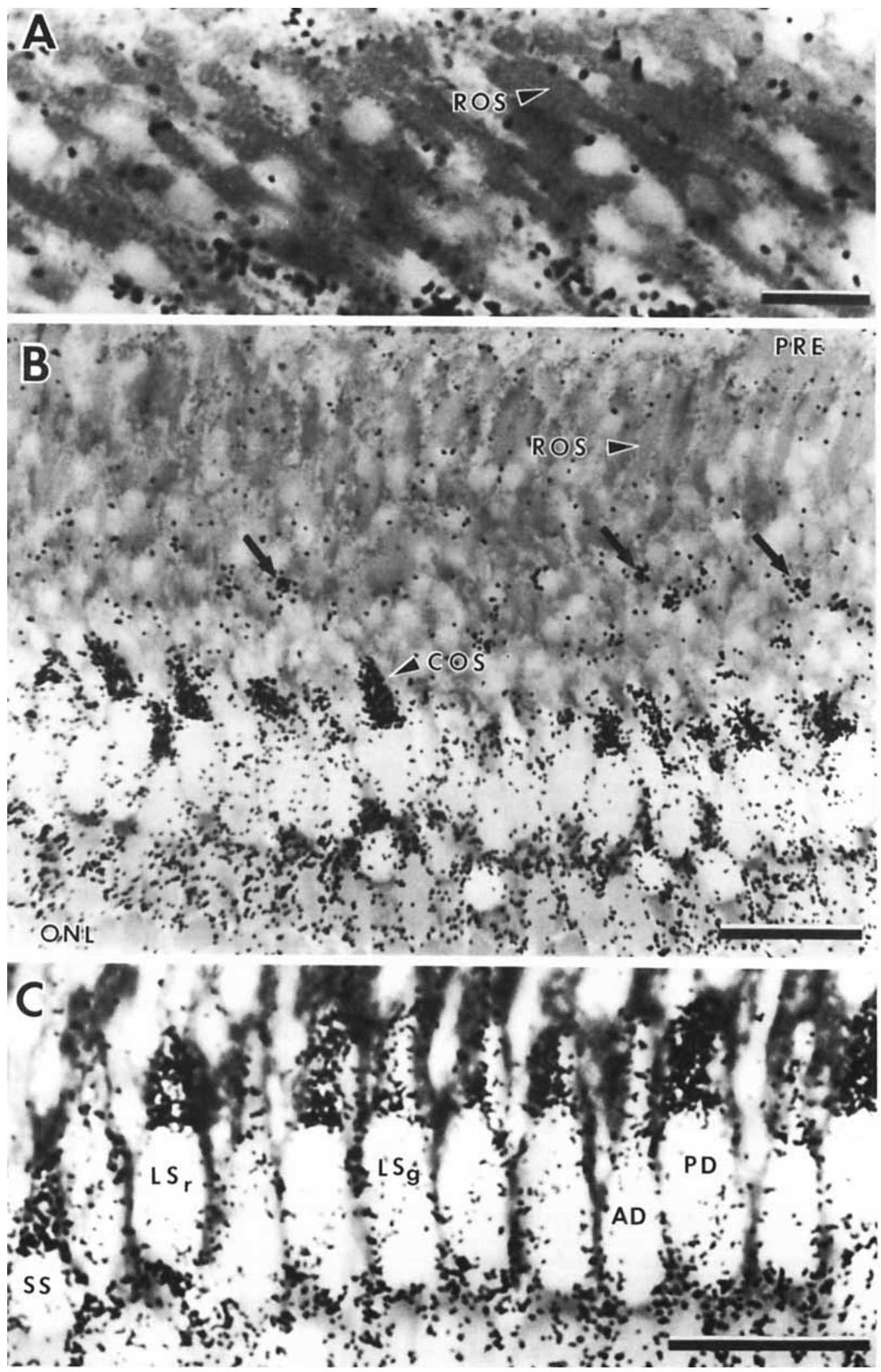

Fig. 1. Light microscopic autoradiographs of the retina from a juvenile goldfish labeled with ${ }^{3} \mathrm{H}$-fucose. A. Rod outer segments (ROS) are unlabeled. $B$. Lower magnification of the same retina, from pigmented retinal epithelium (PRE) to outer nuclear layer (ONL). The heaviest accumulations of silver grains are over cone outer segments (COS). Arrows point to shed cone outer segment tips. C. The heaviest labeling is over outer segments of short single (SS), principal double (PD), and some long single (LSr) cones; other long single (LSg) and accessory double cones (AD) are moderately labeled. Calibration bars: $\mathrm{A}, \mathrm{C}=10 \mu \mathrm{m} ; \mathrm{B}=20 \mu \mathrm{m}$ 

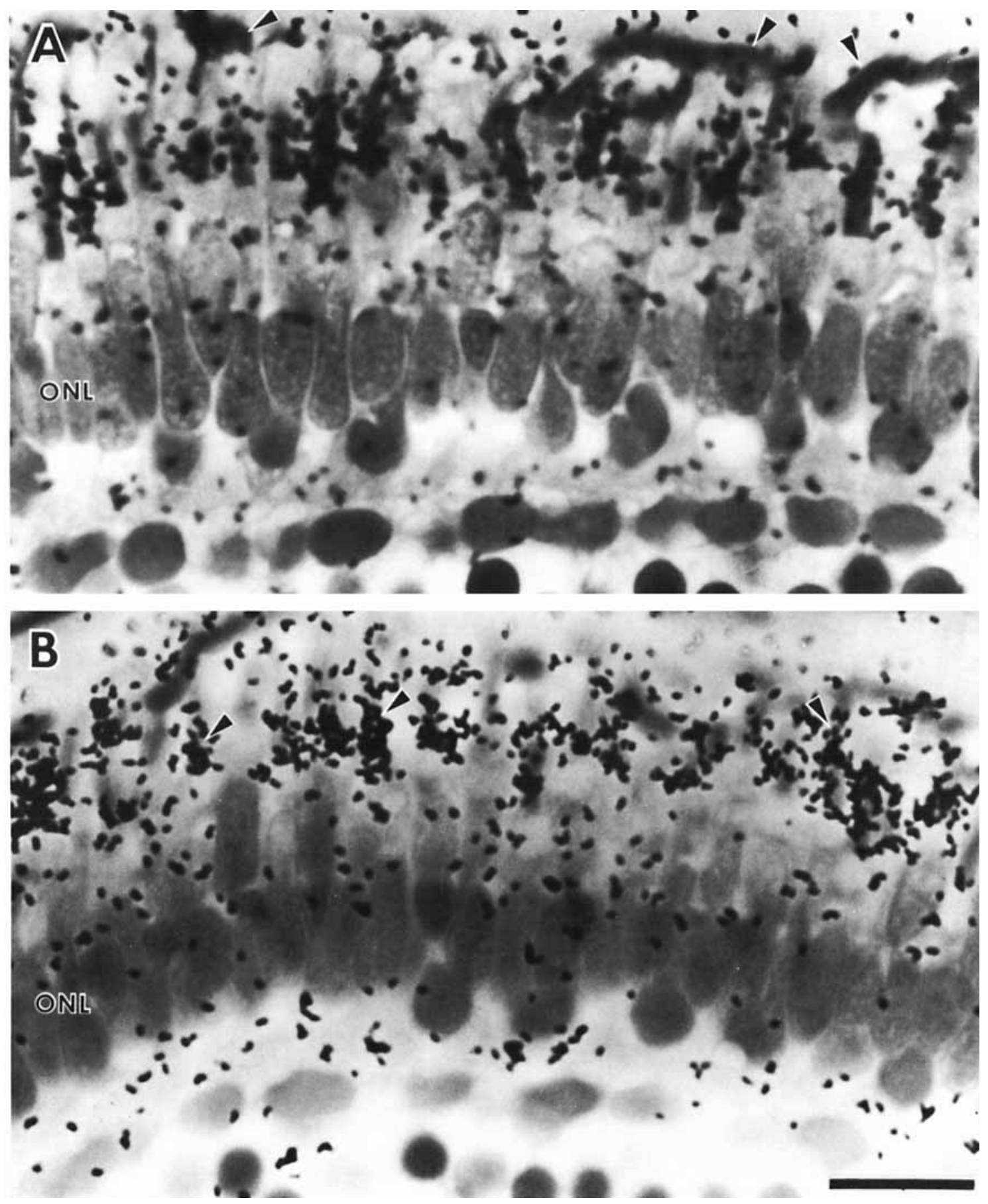

Fig. 2. Light microscopic autoradiographs of the retina from a larval goldfish labeled with ${ }^{3} \mathrm{H}$ fucose. A. Focused on the tissue; rod outer segments (arrowheads) are unlabeled. B. Focused on the silver gains; cone outer segments (arrowheads) are labeled. Outer nuclear layer (ONL). Calibration bar: $\mathrm{B}=10 \mu \mathrm{m}$, also applies to $\mathrm{A}$. 


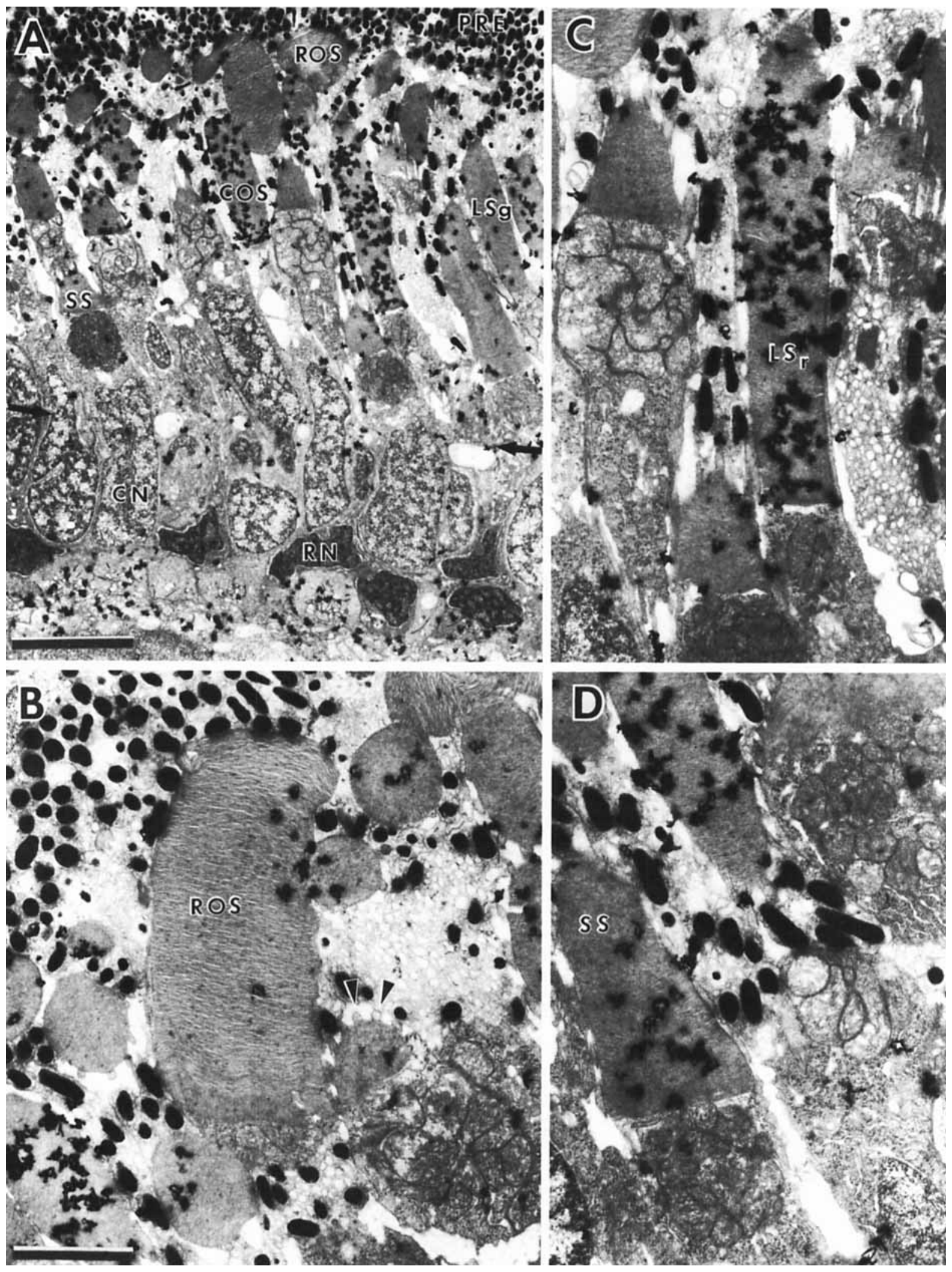

Fig. 3. Electron microscopic autoradiographs of a larval retina labeled with ${ }^{3} \mathrm{H}$-fucose. The plane of the section was slightly oblique. A. Pigmented retinal epithelium (PRE), cone outer segments (COS), rod outer segments (ROS), short single (SS) cone, long single green (LSg) cone, external limiting membrane (arrow) cone nuclei (CN), rod nuclei (RN). B Unlabeled rod outer segment; the PRE runs diagonally at the upper left; calycal processes (arrowheads). C. Long single red (LSr) cone. D. Short single cone. Calibration bars: $\mathrm{A}:=5 \mu \mathrm{m} ; \mathrm{B}=2 \mu \mathrm{m}$, also applies to $\mathrm{C}$ and $\mathrm{D}$. 


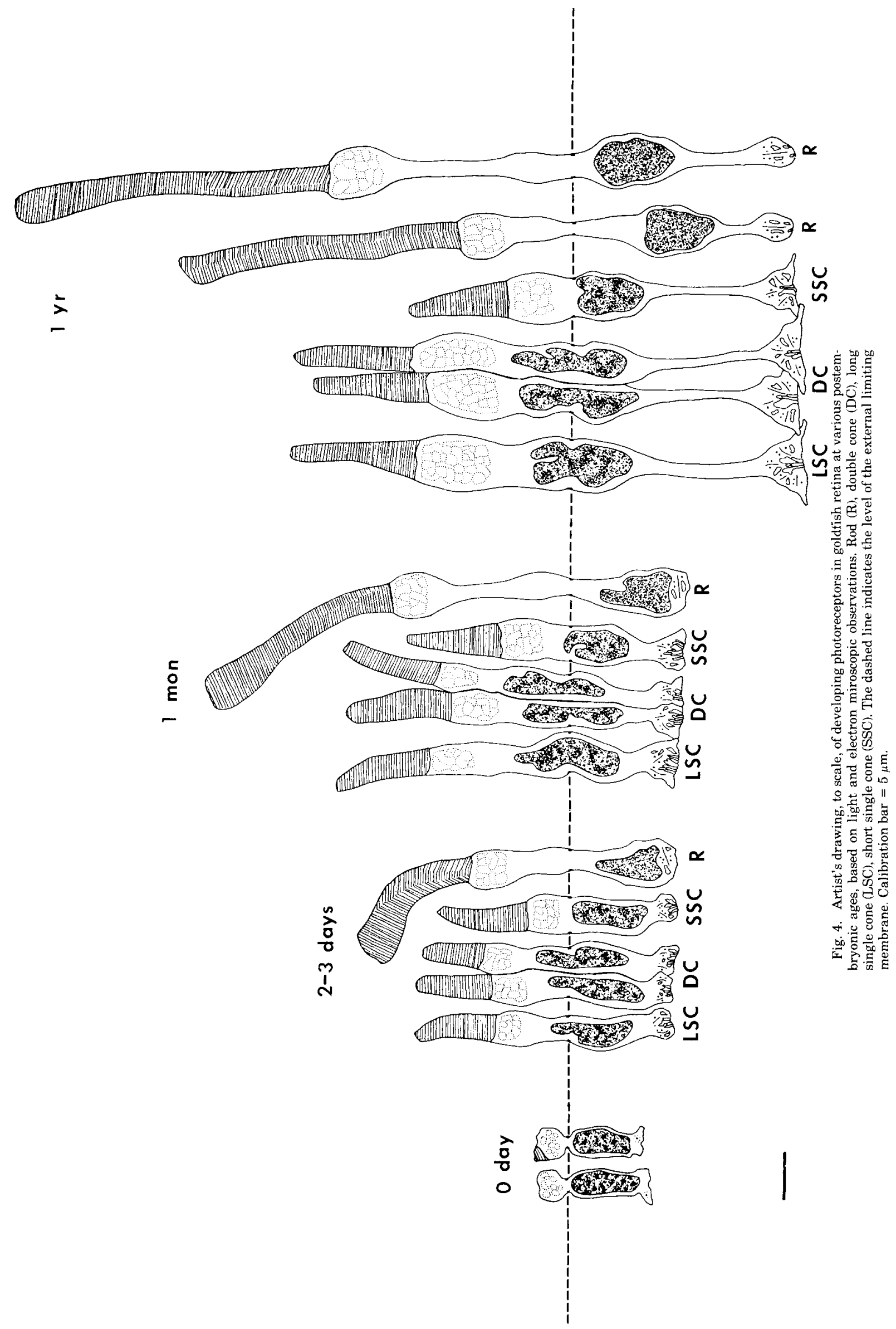




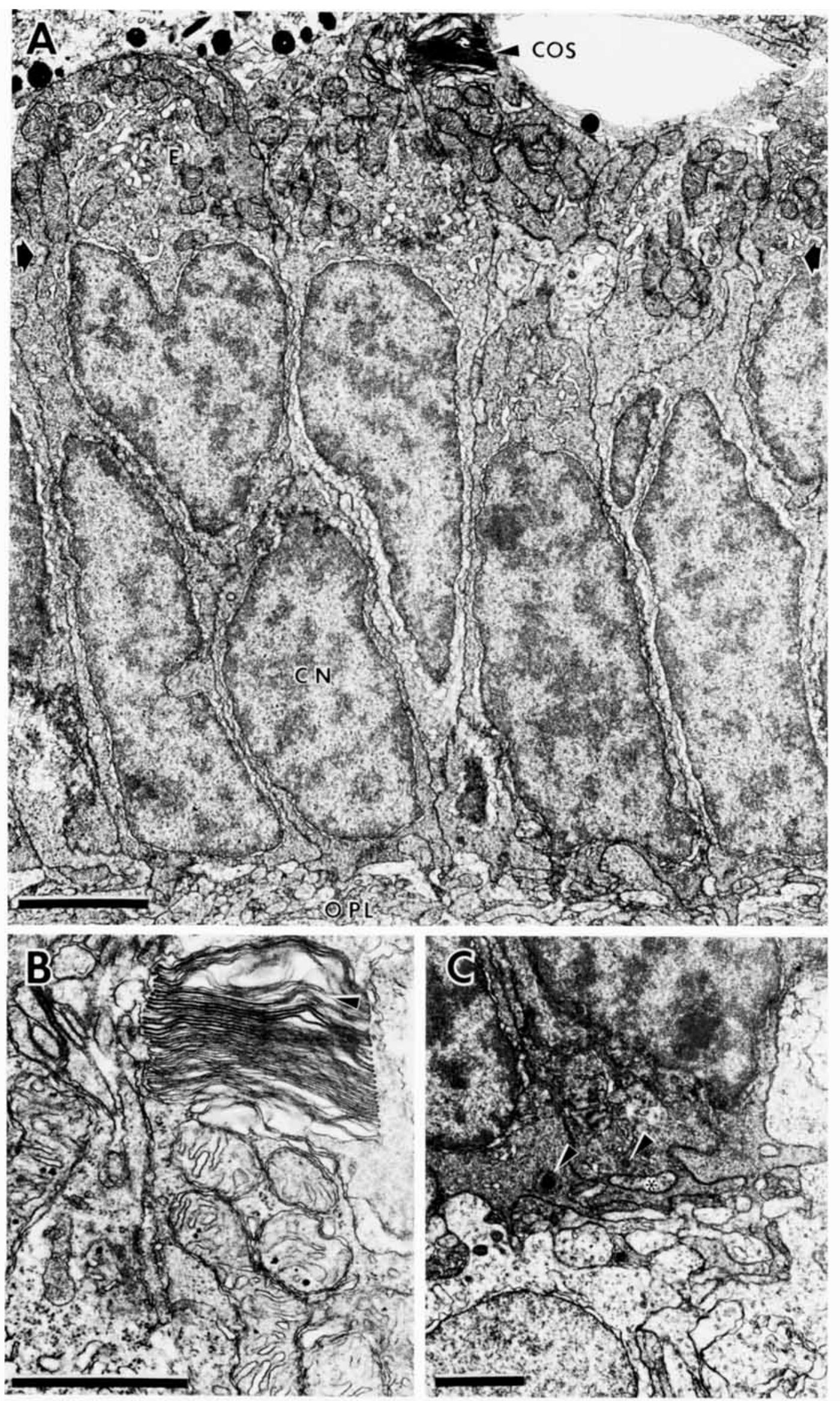


inner and outer segments of developing photoreceptors were measured on camera lucida drawings from 3- $\mu \mathrm{m}$ methacrylate sections in which the melanin in the pigment epithelium had been bleached with $1 \%$ potassium permanganate followed by $1 \%$ oxalic acid (Humason, '72). The advantage of using $3 \mu \mathrm{m}$ methacylate rather than the more standard $0.5-1-\mu \mathrm{m}$ epoxy sections is that in the thicker sections there is a greater probability that for any given photoreceptor the entire outer segment from base to apex will be included within the section. This consideration proved to be especially critical for rod outer segments, which reached lengths of over $30 \mu \mathrm{m}$ in some retinas. Care was taken to draw only those photoreceptors in which the entire outer segment, as well as the inner segment, could be seen.

All measurements were made in the central, most mature part of the retina in light-adapted specimens. Dimensions of the outer segment and the ellipsoid of the inner segment were recorded for each photoreceptor that was drawn. No corrections were made for histological shrinkage, which was estimated to be $15 \%$.

\section{RESULTS}

\section{Identification of rods and cones with ${ }^{3} \mathbf{H}$-fucose}

Figure 1 shows the differential labeling of ROS and COS with ${ }^{3} \mathrm{H}$-fucose in a juvenile fish. ROS are unlabeled (Fig. 1A); COS are heavily labeled (Fig. 1C). These results confirm those of Bunt and colleagues (Bunt and Klock, '80a,b; Bunt and Saari, '82), who first described the differential labeling of photoreceptors with ${ }^{3} \mathrm{H}$-fucose in adult goldfish. They observed, as these preparations also show (Fig. 1B,C), that the density of labeling over cone outer segments varies systematically with photoreceptor type (Marc and Sperling, '76; Stell and Hárosi, '76): the principal members of the double cone pairs and most of the long single cones (both absorb maximally at long wavelengths and are therefore designated "red cones") as well as the short single (blue) cones are heavily to moderately labeled (Fig. 1C); the accessory members of the double cone pairs and the remainder of the long single (green) cones are lightly labeled (Fig. 1C).

A similar pattern was seen in the retinas of larval goldfish. The best preparations were those with a 48-hour incorporation period. For example, in a fish injected with ${ }^{3} \mathbf{H}$ fucose at 3 days after hatching and killed 2 days later, all of the COS are labeled (Fig. 2B). A few unlabeled profiles appear to be outer segments; they are oriented horizontally and are for the most part sclerad to the COS (Fig. 2A). These are believed to be the earliest ROS. The retina of a 7-day-old larval fish, injected with ${ }^{3} \mathrm{H}$-fucose on day 5 , is shown in the electron microscopic autoradiographs in Fig. ure 3 . Here the unlabeled profiles can be more certainly identified as ROS. They curve upward beneath the pigment epithelium (Fig. 3A,B); the narrower, straight COS are labeled (Fig. 3A,C,D). The most heavily labeled COS are either long singles or principle doubles (Fig. 3C). Short

Fig. 5. Electron micrographs of the retina from a newly hatched goldfish. A. Nuclei of cones $(\mathrm{CN})$ are tall and columnar and the presumptive cone ellipsoids $(E)$ protrude into the subretinal space sclerad to the external limiting membrane (arrows). In one cone, the outer segment (COS) has begun to develop, and is shown at higher magnification in $\mathrm{B}$. At the base of the cone nuclei is the outer plexiform layer (OPL), shown at higher magnification in C. B. Developing outer segment lamellae (arrowhead) of a young cone. C. Globular presumptive synaptic ribbons (arrowheads) with surrounding halo of synaptic vesicles and invaginating processes $\left({ }^{*}\right)$ at the base of the cones. Calibration bars: $\mathrm{A}=2 \mu \mathrm{m} ; \mathrm{B}$ and $\mathrm{C}=1 \mu \mathrm{m}$. single COS are heavily to moderately labeled in the larval retinas (Fig. 3D) Short single cones could be distinguished from other cone types even in the early larval retina by the increased electron density of mitochondria in the ellipsoid, the nearness of the inner segment to the external limiting membrane, and the location of the nucleus vitread to the external limiting membrane (Fig. 3A). Other long single or accessory double COS are weakly labeled (Fig. $3 \mathrm{~A}$ ).

Note that there are proportionately many fewer ROS than COS in the retinas of larval fish (Figs. 2,3) compared to juvenile fish, in which the ROS greatly outnumber the COS (Fig. 1).

The following features are characteristic of ROS in the larval retina and serve to distinguish them from cones: (1) they are wider than COS (Figs. 2, 3); (2) the interlamellar spacing is less regular than in COS and the ROS lamellae tend to be less flat and wavy (see below, Figs. 6A,7); (3) the distal ends of the ROS, where they approach the pigment epithelium, are bent parallel to it, whereas COS are straight (Figs. 2,3).

\section{Maturation of rods and cones}

Figure 4 depicts the progressive differentiation of photoreceptors in the retinas of larval and juvenile goldfish. This is a schematic drawing based on light and electron microscopic observations that are summarized next.

In one of three fish examined on the day of hatching, a few cones in the central, most mature part of the retina had tiny outer segments, with a stack of about 20 or 30 membranous lamellae (Figs. 4, 5A,B), but most cones at this stage have only a presumptive inner segment with accumulations of granular and agranular reticulum and mitochondria (Figs. 4, 5A). The pedestal of the cone is flattened and contains clear synaptic vesicles (about 40-nm diameter) some of which form halos around dense globular inclusions (Fig. 5C) which subsequently develop into synaptic ribbons (Smelser et al., '74; Spira, '75; McArdle et al., '77; Grün, '80). A few processes from postsynaptic elements (horizontal or bipolar cells) invaginate the cone pedestal (Fig $5 \mathrm{C}$ ), but the conical pedicle of the mature cone has not yet developed.

By 1 day after hatching, COS are much longer (about 100-200 lamellae) and well organized (Fig. 6A). Several (up to about 40) postsynaptic processes have invaded the squat cone pedestal, and elongated synaptic ribbons with their accompanying halo of vesicles are seen (Fig. 6B-D). In the 1-day-old and older larvae, a few ROS are present (Figs. 6A, $7 \mathrm{~A}, \mathrm{~B})$. Compared to the developing COS, the young ROS are wider and the lamellae are interupted by clefts or incisures which in cross sections give a scalloped shape to the perimeter of the OS (Fig. 6A) and in longitudinal sections produce a wavy appearance (Fig. 7A,B). Such incisures are characteristic of rods, but not of cones, and they have been described previously in developing ROS of tadpoles (Nilsson, '64) and in mature rods of fish (Borwein and Hollenberg, '73) and other species (reviewed by Cohen, '72). In the myoid region of the inner segment of the rods, just vitread to the ellipsoid, are tightly packed, parallel stacks of granular endoplasmic reticulum with associated vesicular material (Fig. 7D). Myoids of cones are less dense than those of rods and also contain abundant vesicular material in this region (Fig. 7A,D).

In the outer nuclear layer along the border of the outer plexiform layer occasional pyramidal or polygonal nuclei of rods are found vitread to cone nuclei. Rod nuclei are often 

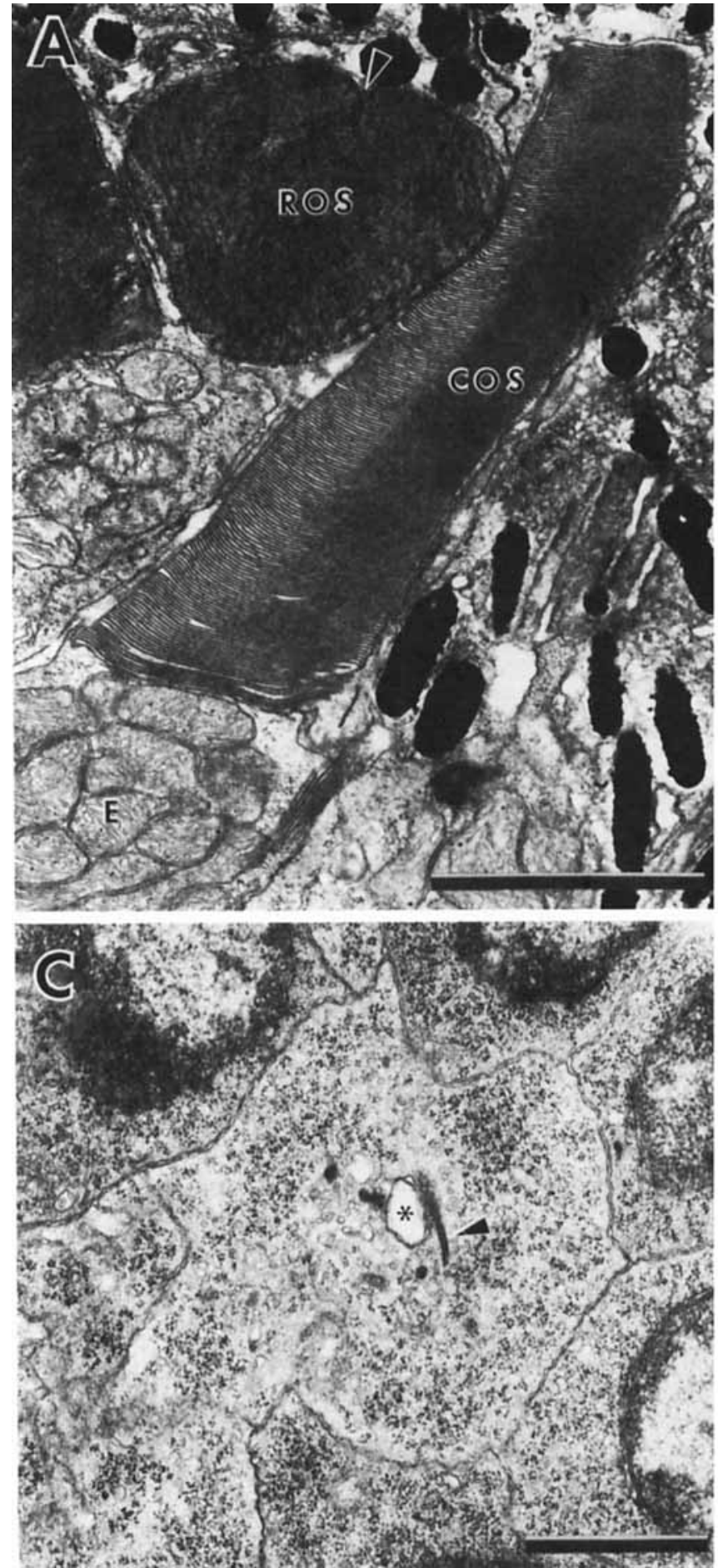

Fig. 6. Electron micrographs of the retinas from 1- and 2-day-old larval goldfish. A. Cone outer segment (COS) and cone ellipsoid (E), rod oute segment (ROS), incisure (arrowhead). B. Cone nuclei (CN); synaptic pedestals containing synaptic ribbons (arrowheads) and invaginating processes
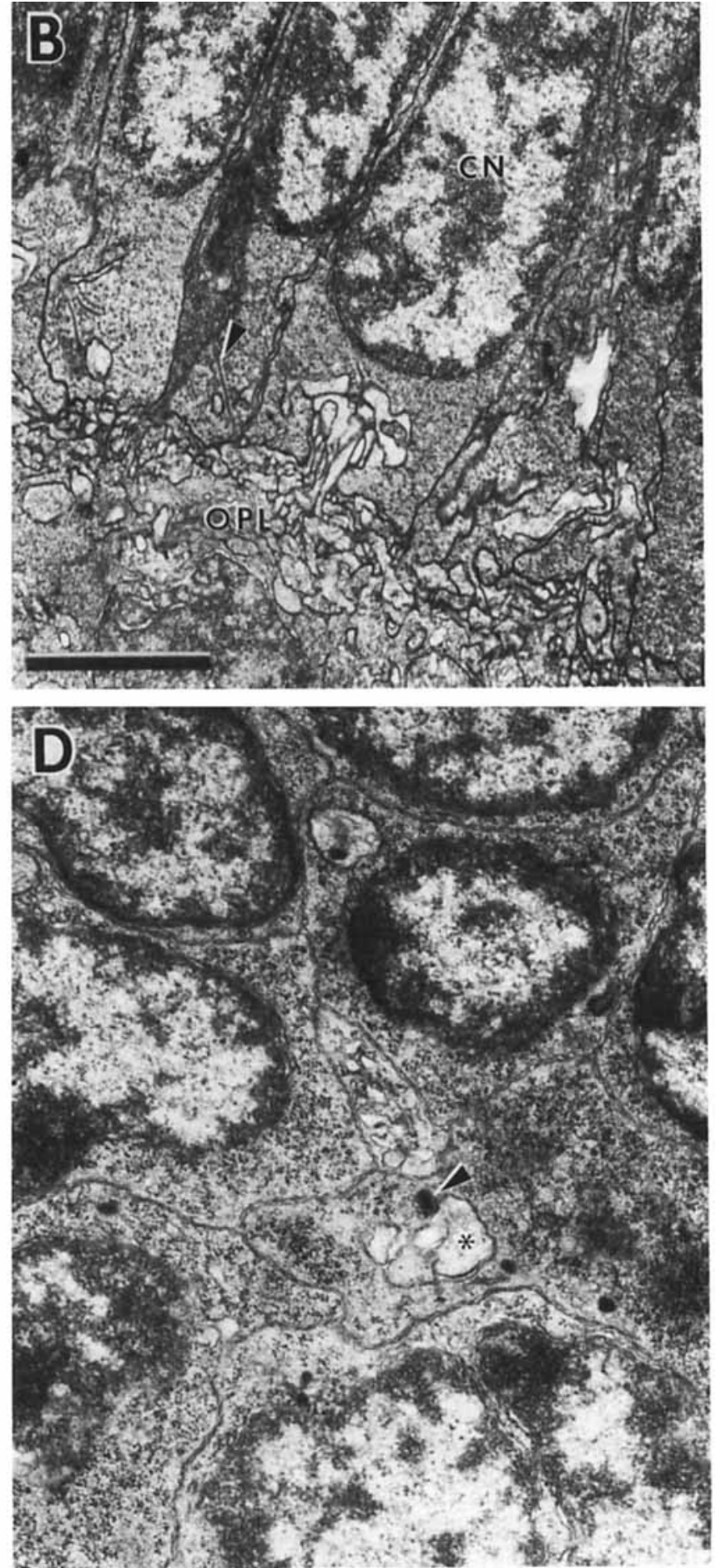

from the outer plexiform layer (OPL). C,D. Synaptic pedestals of developing cones cut in tangential section contain synaptic ribbons (arrowheads) with a halo of synaptic vesicles and invaginating processes (*). Calibration bars: $A$ and $B=2 \mu \mathrm{m} ; C=1 \mu \mathrm{m}$, also applies to $\mathrm{D}$ 


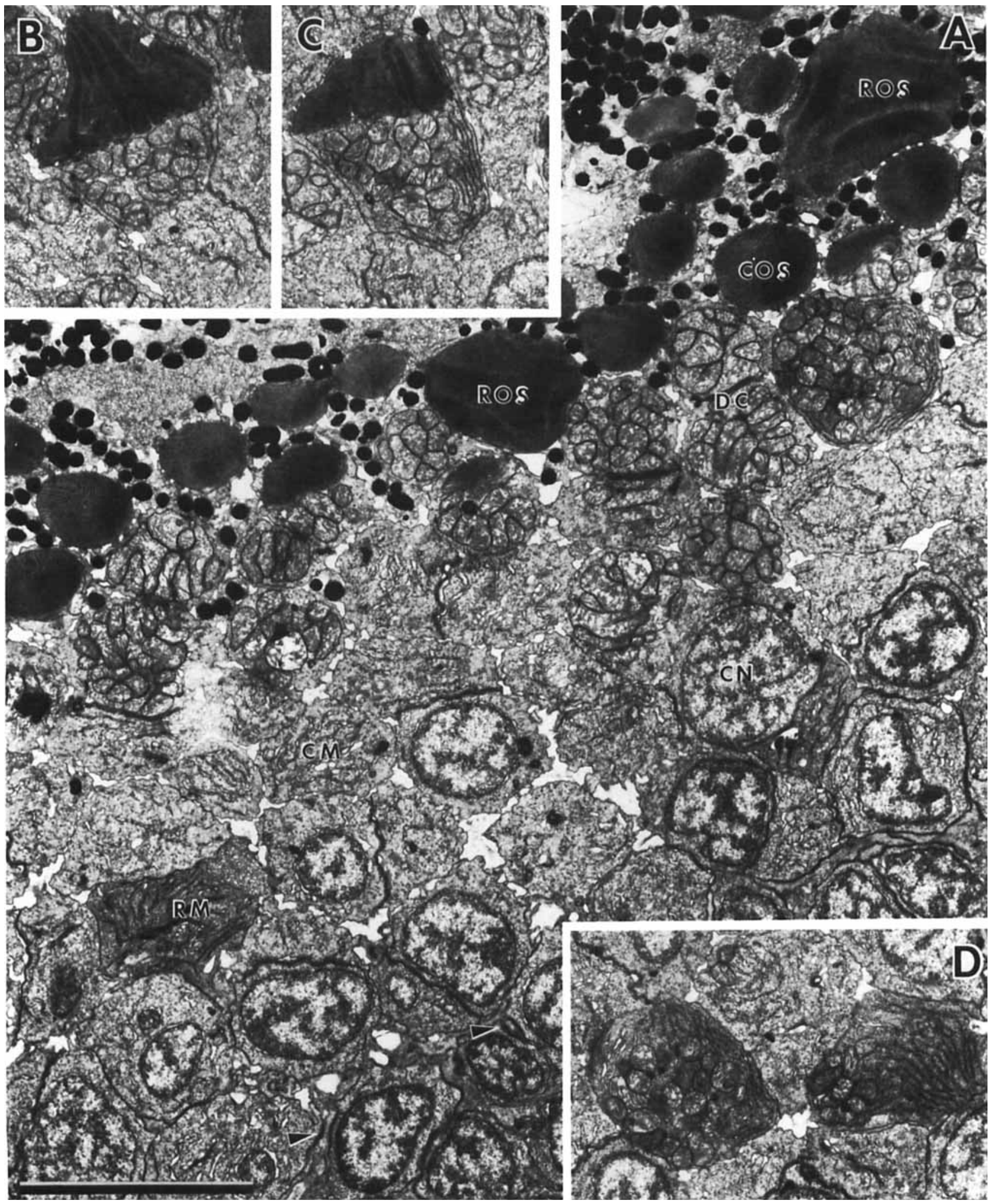

Fig. 7. Electron micrographs of a tangential section through the retina of a 7-day-old larval goldfish. A. The section passes through the external limiting membrane in the lower half (represented as a series of dense appositions between adjacent cell membranes; arrowheads) and the pigmented retinal epithelium at the top; rod outer segment (ROS), cone outer segment (COS), double cone (DC), rod myoid (RM), cone myoid (CM), cone nucleus (CN). B and C. Two examples of rod outer segments with attached ellipsoids. D. Two examples of rod myoids. Calibration bar: $\mathrm{A}=5 \mu \mathrm{m}$, also applies to B-D. 

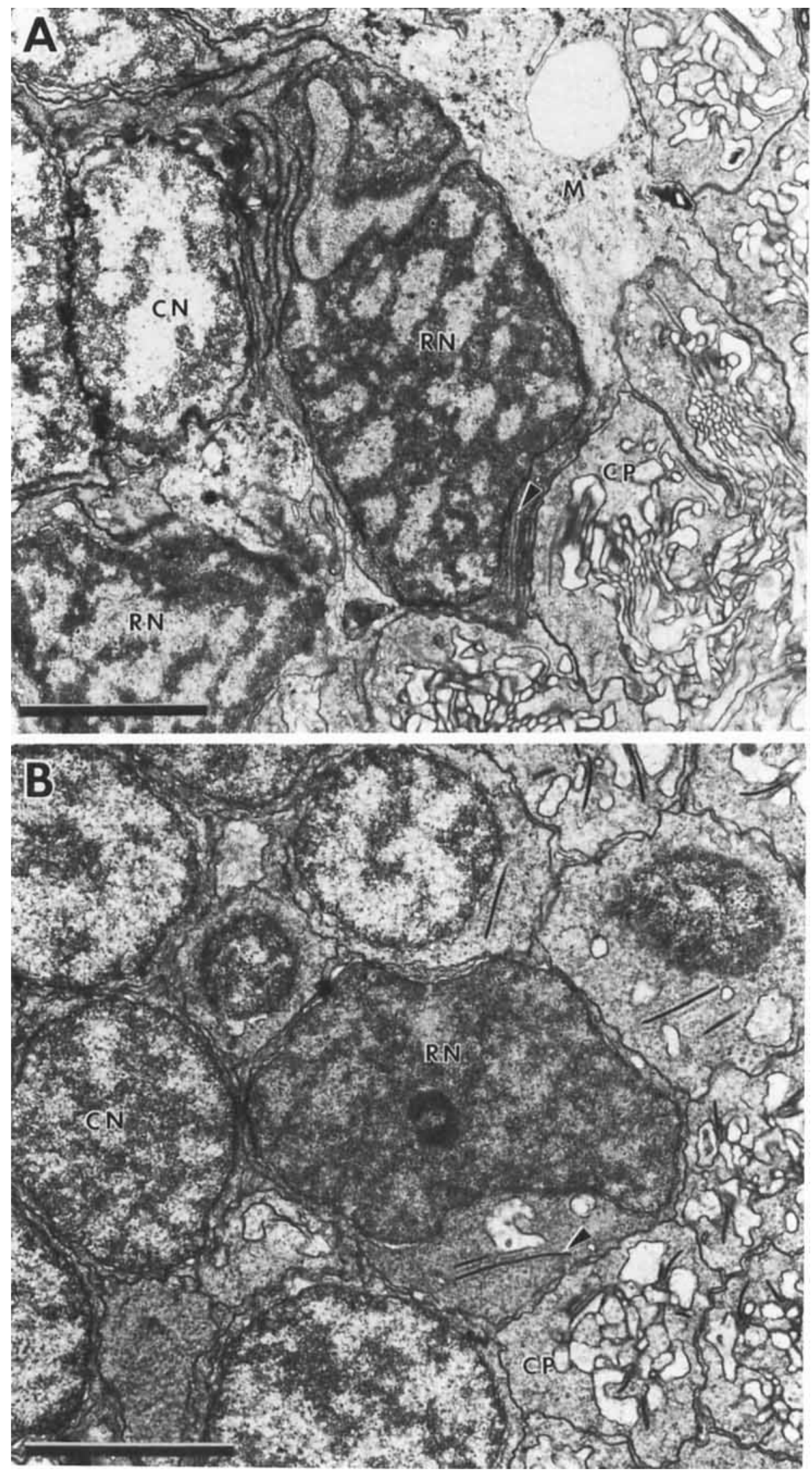
deeply lobulated and have dense chromatin (Fig. 8A). The young rods have a perinuclear synaptic ribbon with accompanying synaptic vesicles and invaginating postsynaptic processes (Figs. 8A,B).

The cone pedicles mature rapidly, and within a few days look much like those in adults. This is illustrated in Figure 9, which compares tangential sections through the photoreceptor synaptic layer of a 7-day-old, a 1-month-old, and a juvenile fish (3.8 cm standard length). Larval cone pedicles are small $(2.63 \pm 0.39 \mu \mathrm{m}$ diameter, mean \pm S.D. of 43 measurements) but contain multiple ribbons, arciform densities, and invaginating processes (Fig. 9A). Cone pedicles in 1-month-old fish (Fig. 9B) are still small (3.01 \pm 0.38 $\mu \mathrm{m}$ diameter, mean \pm S.D. of 30 measurements) compared to those in juvenile fish (Fig. 9C), which average $4.85 \pm$ $0.08 \mu \mathrm{m}$ diameter (mean + S.D. of 18 measurements). Aside from their small size, the membrane specializations at the regions of junctional apposition between the cone pedicles and the invaginating dendritic profiles are simpler in the immature than in the mature retina (compare Fig. 9A,B to $\mathrm{C}$ ).

In the mature teleost retina, rod spherules are easily distinguished from cone pedicles (Stell, '67; Cohen, '72; Borwein and Hollenberg, '73; Braekevelt, '82). Spherules are smaller $(2.27 \pm 0.31 \mu \mathrm{m}$, mean \pm S.D. of 53 measurements from one juvenile retina) and more electron dense than cone pedicles. Rod spherules typically contain only one ribbon whereas cone pedicles have multiple (more than five) ribbons (Fig. 9C). Occasional rod spherules have two ribbons, and reconstructions of four such spherules from serial sections confirmed that there were indeed two separate ribbons, but these double-ribboned spherules are the exception. Rod spherules are clustered in the interstices between cone pedicles (Fig. 9C). In the larval retina, on the other hand, cone pedicles are packed tightly together with little intervening space, and there are no rod spherules (Fig. 9A,B).

In one fish examined at 3 months and in two fish examined at 8 months of age, the photoreceptor terminals in the outer nuclear layer were nearly identical to those in juvenile and adult goldfish, and cone pedicles and rod spherules could be readily distinguished.

In summary, cone pedicles very quickly (in the first few days after hatching) develop a mature appearance: a pendulous foot invaded by numerous processes from secondorder neurons. They are at first small (less than half the diameter of pedicles in the adult retina) but otherwise complete. Rod spherules, in contrast, acquire their mature form only during postlarval stages, between 1 and 3 months after hatching. At early stages rods appear to be synaptically connected to second-order neurons, but the synapses are onto the cell soma rather than onto an axon terminal, or spherule, as in the adult.

\section{Growth of photoreceptors}

The changing dimensions of photoreceptors during postembryonic development are depicted graphically in Figures

Fig. 8. Electron micrographs of rod nuclei in larval goldfish. A. Retina from a 3-week-old fish, cut transversely (radially). Cone nucleus (CN), rod nucleus (RN), cone pedicle (CP), Müller cell cytoplasm (M), synaptic ribbon (arrowhead). B. Retina from a 1-week-old fish, cut tangentially. Calibration bars: $A$ and $B=2 \mu \mathrm{m}$.
10 and 11. On the abscissa is plotted the lens diameter, which is an accurate and convenient index of the size of the eye (Johns, '82) and is an approximate measure of age (Johns and Easter, '77). (Age could not be used as the dependent variable because it was known only for fish reared in the laboratory, which had lens diameters less than $1 \mathrm{~mm}$ and were less than 3 months old.) The smallest fish were 3 days old and the largest, about 4 years old. Standard body lengths ranged from .45 to $20 \mathrm{~cm}$.

Figure $10 \mathrm{~A}$ shows OS lengths of rods and the four major types of cones. Note that COS of principal double, accessory double, and long single cones are similar in length and elongate at the same rate as the fish grows. Short single COS are, as their name implies, shorter than the others. The first point on the graph, the filled square, represents a combined average of COS lengths for all cone types including short singles. Short single COS do not increase significantly in length as the eye grows; the slope of the leastsquares linear regression line (see legend to Fig. 10) is not significantly different from zero (Howell, '82). This lack of growth of short single COS can also be seen in the schematic of Figure 4, which is drawn to scale. The other COS, in contrast, do elongate, initially at a rapid rate and then more slowly. Their average length increases by $40 \%$ as lens diameter increases from 0.14 to $0.33 \mathrm{~mm}$, but only by another $30 \%$ with further increase in lens diameter to 4.1 $\mathrm{mm}$. Both increases are significant $(\mathbf{P}<.001)$.

The ROS show a different pattern of growth. First, there is a phase of rapid elongation, represented by the first four points on the ROS curve in Figure 10A (lens diameters less than $1 \mathrm{~mm}$ ). During this period, ROS lengths increase three fold, from about 10 to $30 \mu \mathrm{m}$. Then there is a phase of instability, represented by the next five points, when mean ROS lengths vary between about 20 and $32 \mu \mathrm{m}$ (lens diameters of $1-2 \mathrm{~mm}$ ). The oscillating curve through these points was drawn by a computer program (see legend to Fig. 10A) as a best fit to the data; it does not imply that ROS in a given retina cyclically shrink and grow, but rather that there is variability in ROS lengths among fish during this juvenile growth period. The mean ROS length in juveniles was $27.7 \pm 6.23 \mu \mathrm{m}(\mathrm{n}=119 \mathrm{ROS}$ from five retinas). In the final phase (lens diameters greater than $2 \mathrm{~mm}$ ) ROS length tends to stabilize around a mean length of $22.9 \pm 4.95 \mu \mathrm{m}$ $(n=120$ ROS from four retinas). An analysis of heterogeneity of variance showed significantly more variability in ROS lengths in fish with lens diameters of 1-2 mm compared to those over $2 \mathrm{~mm}(\mathrm{P}<.01)$. A t-test to compare the means revealed the difference to be highly significant $(\mathrm{P}<$ .001). Therefore, the somewhat surprising implication is that ROS are on average shorter in adult goldfish than in juveniles.

Another unexpected feature of ROS development is shown in Figure 10B. The widths of ROS decrease significantly with growth. The least-squares linear regression (see legend to Fig. 10) has a negative slope that is significantly different from zero $(P<.01)$. ROS in adult fish are $35 \%$ narrower than those of larvae. The widths of COS, in contrast to ROS, increase with growth of the eye (data not graphed), from about 2 to $4 \mathrm{~mm}$.

Figure 11 shows the increase in length of the ellipsoid region of the inner segments of cones and rods with growth of the eye. For all types of cones, the increase in length is over threefold (Fig. 11A,B). In each eye, the ellipsoids in principal and accessory double cones and long single cones are equivalent in length; short single cones are shorter than the other types. The rate of elongation of cone 

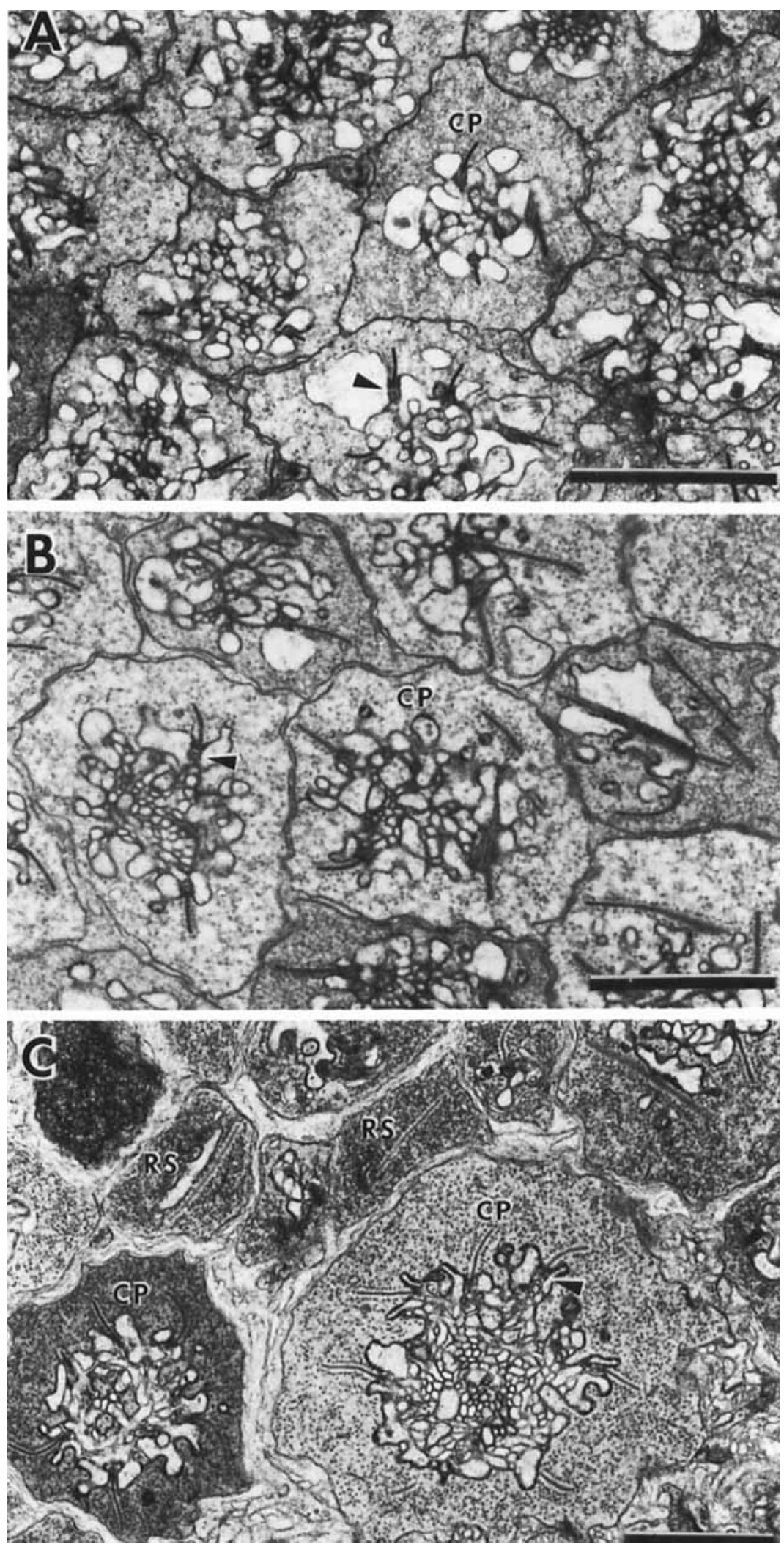

Fig. 9. Electron micrographs of tangential sections through the synaptic terminals of photoreceptors. A. Seven-day-old larval goldfish; cone pedicles (CP); arciform density (arrowhead). B. One-month old goldfish. C. Juvenile goldfish; rod spherules (RS). Calibration bars $=2 \mu \mathrm{m}$. 


\section{OUTER SEGMENT LENGTH}

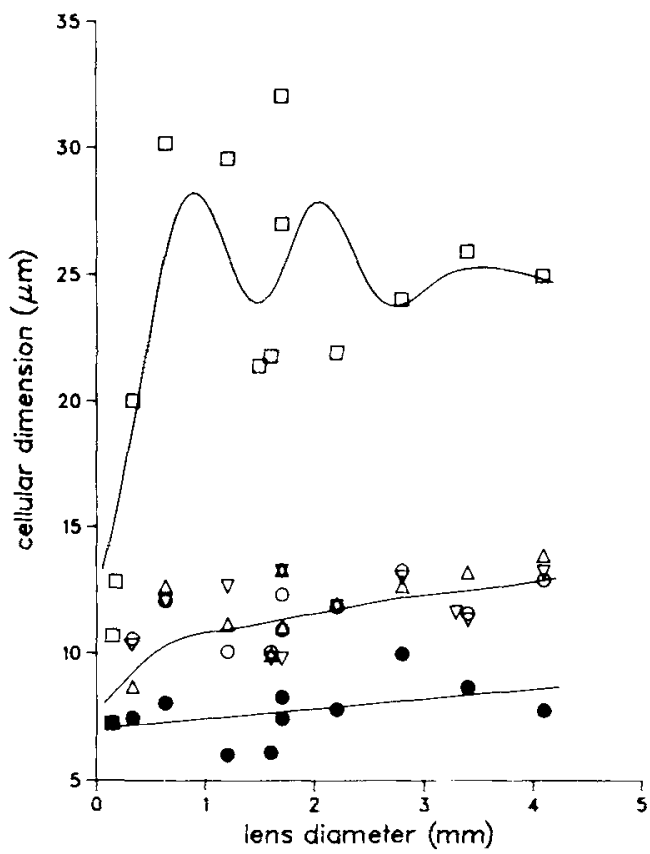

OUTER SEGMENT WIDTH

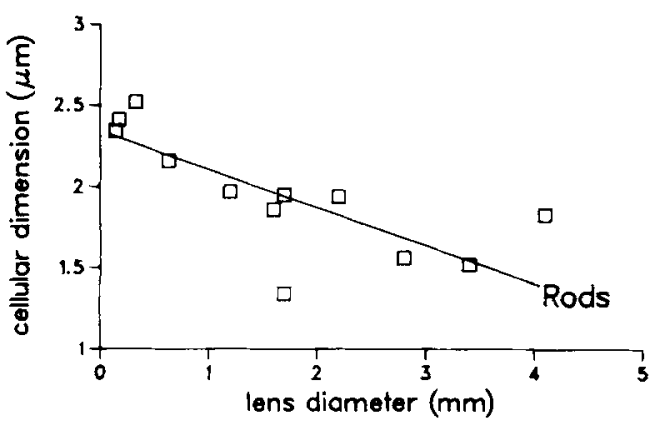

Fig. 10. Changing lengths and widths of outer segments during postembryonic growth. A. For the cones, each point represents the mean outer segment length of five to 17 cones from one retina, except that the first point ffilled square) represents the combined mean of 65 cones of all types from seven retinas of fish 3-10 days old. For the rods, each point is the mean ROS length of $13-50$ rods from one retina. The curves drawn through the points were generated by a computer graphics program (Tell-A-Graf, proprietary software of Integrated Software Systems Corp., San Diego). The upper two curves were computed using a parametric spline-smoothing function. The line through the points for short single COS is the least-squares linear regression $(y=0.34 \mathrm{x}+7.1, \mathrm{r}=.42)$. Principal double $(\mathrm{PD})$, accessory double (AD), long single (LS) and short single (SS). B. Each point is the mean ROS width of $13-50$ rods from one retina. The least squares linear regression is $\mathrm{y}=-0.21 \mathrm{x}+2.3, \mathrm{r}=-.73$

\section{ELLIPSOID LENGTH}

A

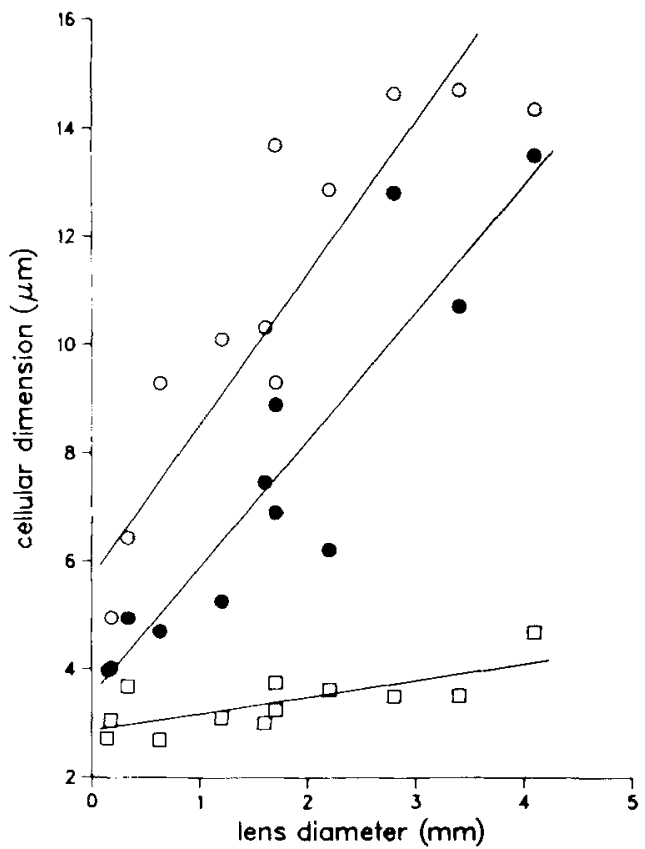

Legend

O LS cones

- SS cones

D Rods

B

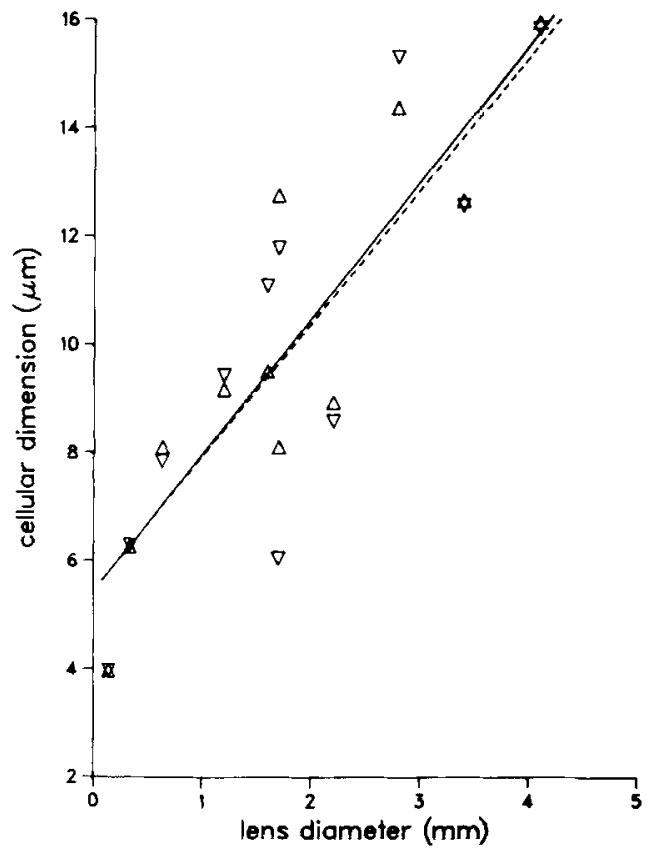

Legend

$\triangle \underline{P D}$ cones

$\nabla$ AD cones

Fig. 11. Changing lengths of inner segment ellipsoids during postembryonic growth. The sampling strategy and abbreviations are as described in Figure 10. The curves drawn through the data are the least-squares linear regressions, $\mathrm{PD}: \mathrm{y}=2.6 \mathrm{x}+5.4, \mathrm{r}=.89 ; \mathrm{AD}: \mathrm{y}=2.6 \mathrm{x}+5.2, \mathrm{r}=$ $.85 ;$ LS: $\mathrm{y}=2.6 \mathrm{x}+6.0, \mathrm{r}=.89$; SS: $\mathrm{y}=2.4 \mathrm{x}+3.5, \mathrm{r}=.92$; Rods: $\mathrm{y}=$ $0.31 x+2.9, r=.73$ 
ellipsoids is equivalent for all cone types, as shown by the similarity in slopes of the linear regression equations (see legend to Fig. 11). The widths of the cone ellipsoids also increase, but only twofold (from $3.5 \mu \mathrm{m}$ in the smallest eyes to $7.0 \mu \mathrm{m}$ in the largest ones; data not graphed). Rod ellipsoids are smaller than those of cones and spherical in shape. They increase in length with growth of the eye (Fig. 11A), but only by $38 \%(\mathrm{P}<.01)$.

\section{DISCUSSION}

The two major goals of this study were (1) to identify ROS in larval goldfish by differential labeling with ${ }^{3} \mathrm{H}$-fucose and by ultrastructural criteria and (2) to describe quantitatively the morphogenesis of rods and cones. The study was motivated by previous work with ${ }^{3} \mathrm{H}$-thymidine autoradiography which dealt with the order of production of photoreceptors in the retinas of fish. From that work it was known that some cones become postmitotic in the embryo, but rods are produced only postembryonically (Sandy and Blaxter, ' 80 ; Johns, '82) and continue to be generated within the differentiated retina for a prolonged period, in some species into adult life (Johns and Fernald, '81; Szamier and Ripps, '83). From these observations several questions arise. How is histogenesis of the photoreceptor layer affected by the wide dispersion in times of origin of its cells? How are the late-developing rods integrated into the differentiated retina? Is the cone population stable, in that similar types and proportions are present in larvae and adults, or is it, like the rod population, altered as the retina matures?

\section{Identification of larval rods and cones}

Immature ROS in the larval retina, like those in the adult, failed to incorporate ${ }^{3} \mathrm{H}$-fucose, whereas $\mathrm{COS}$ of all types were diffusely labeled. Some cones in the larval retina were weakly labeled, whereas others were more heavily labeled, as in adult goldfish (Bunt and Klock, '80a,b; Bunt and Saari, '82). This differential labeling aided in the morphological identification of the immature photoreceptors. Other investigators (Ditto, '75; Kinney and Fisher, '78) have faced similar difficulties in trying to identify immature rods and cones in larval amphibians since all photoreceptors in these animals are quite similar morphologically during early stages of differentiation. As a marker they used ${ }^{3} \mathrm{H}$-leucine, which is incorporated differentially by ROS and COS (Young, '69). The advantage of ${ }^{3} \mathrm{H}$-fucose, used in the present study, is that in the goldfish retina it discriminates not only between rods and cones but also between red- and green-sensitive cones (Bunt and Klock, '80a).

The principal types of cones known to be present in the adult goldfish retina (Stell and Lightfoot, 75; Stell and Hárosi, '76; Marc and Sperling, '76) can be recognized in the larval retina as early as 2 days based on morphological features and on differential uptake of ${ }^{3} \mathrm{H}$-fucose. This includes double cones and long single and short single cones. (The more rare miniature short single and long single cones were also seen in older larvae, but they were not studied.) The origin of double cones (or twin cones, in which the two members of the pair are identical) in the teleost retina has been a subject of interest and debate for many years (Walls, '67). The consensus seems to be that double cones arise from the fusion of separately generated single cones (Blaxter and Staines, '70; Wagner '74; Sandy and Blaxter, '80; Branachek and BreMiller, '84). The results of this study indicate that in goldfish., double cones are present by 2 days of age, at a stage when the animal has not yet begun feeding and does not yet exhibit coordinated swimming movements. By about 3 days, when feeding commences, all major cone types are present. A similar developmental pattern occurs in a cichlid fish, Nannacara (Wagner, '74). These fish thus have a full complement of cone types when visual behavior begins. Developing sole (Solea solea) differ in that twin cones appear suddenly at metamorphosis, by fusion of mature single cones, after a long ( 6 weeks) and visually active period of larval development (Sandy and Blaxter, '80).

This study confirms previous observations that rods differentiate after cones in fish (Müller, '52; Wagner, '74; Johns, '82; Branachek and BreMiller, '84) and in mammals (Hollenberg and Spira, '73; Smelser et al., '74; Carter-Dawson and LaVail, '79). Little is known about the functional significance of the different rates of maturation of rods and cones in these retinas. In mammals, development of rods, though late, nevertheless is virtually completed before the eyes open. Larval fish, on the other hand, function for some period without benefit of a morphologically mature or numerically complete population of rods. Branachek ('84) recently examined the electroretinogram (ERG) as an index of photoreceptor function in larval zebrafish (Brachydanio rerio), and found the first evidence of duplex (rod and cone) function at about 2 weeks of age, several days after ROS could first be identified morphologically.

\section{Growth of photoreceptors}

With the exception of short single cones, the COS in creased substantially in length as the eye grew during the larval and juvenile period, and elongated more slowly thereafter. The OS of short single cones did not elongate beyond the length achieved by 3-10 days of age. The inner segment ellipsoids of all cones, including short singles, contimued to lengthen throughout the range of sizes and ages of fish studied (up to about 4 years). The ROS also elongated, by a much greater amount than COS (300\% compared to $70 \%$ ). However, all of the elongation took place during larval and juvenile stages, and subsequently ROS shortened to $80 \%$ of their maximum length.

Another surprising observation was that ROS in larval fish were wider than those in adults; they decreased from 2.5 to $1.5 \mu \mathrm{m}$ in width. The morphogenesis of photoreceptors has been studied previously in several species, including frog (Nilsson, '64; Kinney and Fisher, '78), mouse (Olney, '68), rabbit (McArdle et al., '77), and primate (Smelser et al., '74). Only one of these studies mentioned ROS width, but reported that developing ROS are narrower than in the adult (Nilsson, 64).

The dimensions of adult goldfish photoreceptors reported here agree quite closely with the values reported by O'Day and Young ('79), but are substantially shorter than those reported by Stell and Hárosi (76). The reason for the discrepancy is obscure.

\section{Integration of new rods into the retina}

The immature rods of the larval and juvenile goldfish retina are morphologically different from rods in adults in at least two respects. First, as discussed above, the outer segments are wider and shorter in the larva compared to the adult. Second, the synaptic ribbons and associated synaptic vesicles of the larval rods are located in a paranuclear position, and postsynaptic processes invaginate the base of the cell body in the region of the ribbon. Rod spherules, 
characteristic of the mature retina, were not observed until 3 months of age. Stell and Kock ('84) report that rod spherules can be recognized at 60 hours after hatching in larval goldfish. They used the term "spherule" quite loosely, however, and they actually saw what are described here as paranuclear synaptic specializations (W.K. Stell, personal communication). They report that the organization of rodbipolar contacts in larval goldfish differs from that in adults, but the physiological or behavioral consequences of the difference is not known.

No one has yet analyzed in detail the synaptic connectivity of larval goldfish cones to compare them with the known connectivity patterns of adult goldfish cones (reviewed by Stell and Kock, '84), so the status of their connections is unknown. Nevertheless, since cone pedicles and COS attain a mature morphology more quickly than do comparable structures in rods, the influence of cones on visual function in larval goldfish may be similar to that in adults, whereas the rod system may be slower to develop.

\section{ACKNOWLEDGMENTS}

This work was supported by PHS EY04318. Dr. Jeffrey W. Holcombe, Ms. Patricia K. Rivlin, Ms. Diane Alessi, and Ms. Laurie Sultz provided expert technical assistance. Mrs. Sharon Moskwiak and Ms. Barbara France typed the manuscript. Drs. Stephen S. Easter, William K. Stell, and Edward V. Famiglietti offered helpful suggestions and comments.

\section{LITERATURE CITED}

Allee, W.C., A.J. Finel, and W.H. Hoskins (1940) The growth of goldfish in homotypically conditioned water; a population study in mass physiology. J. Exp. Zool. 84:417-443.

Blaxter, J.H.S., and M. Staines (1970) Pure-cone retinae and retinomotor responses in larval teleosts. J. Mar. Biol. Assoc. UK 50:449-460.

Borwein, B., and M.J. Hollenberg (1973) The photoreceptors of the "foureyed" fish, A nableps anableps L. J. Morphol. 140:405-442.

Braekevelt, C.R. (1982) Photoreceptor fine structure in the goldeye. Anat. Embryol. 165:177-192.

Branchek, T. (1984) The development of photoreceptors in zebrafish, Brachydanio rerio. II. Function. J. Comp. Neurol. 224:116-122.

Branchek, T., and R. BreMiller (1984) The development of photoreceptors in zebrafish, Brachydanio rerio. I. Structure. J. Comp. Neurol. 224: $107-115$.

Bunt, A.H., and I.B. Klock (1980a) Fine structure and radioautography of retinal cone outer segments in goldfish and carp. Invest. Ophthalmol. Vis. Sci. 19:707-719

Bunt, A.H., and I.B. Klock (1980b) Comparative study of ${ }^{3}$ H.fucose incorporation into vertebrate photoreceptor outer segments. Vision Res. 20: $739-747$.

Bunt, A.H., and J.L. Saari (1982) Fucosylated protein of retinal cone photoreceptor outer segments: Morphological and biochemical analysis. J. Cell Biol. 92:269-276.

Carter-Dawson, L.D., and M.M. LaVail (1979) Rods and cones in the mouse retina. II Autoradiographic analysis of cell generation using tritiated thymidine. J. Comp. Neurol. 188:263-272.

Cohen, A.J. (1972) Rods and cones. In M.G.F. Fuortes (ed): Handbook of Sensory Physiology, Vol. 7, Physiology of Photoreceptor Organs. New York: Springer Verlag, pp. 63-111.

Davis, T.L., R.F. Spencer, and P. Sterling (1979) Preparing autoradiograms of serial sections for electron microscopy. J. Neurosci. Methods 1:179 183.

Ditto, M. (1975) A difference between developing rods and cones in the formation of outer segment membranes. Vision Res. 15:535-536.

Grün, G. (1980) Developmental dynamic in synaptic ribbons of retinal receptor cells (Tilapia, Xenopus). Cell Tissue Res. 207:331-339.

Hollenberg, M.J., and A.W. Spira (1973) Human retinal development: Ultrastructure of the outer retina. Am. J. Anat. 137:357-386.

Howell, D.C. (1982) Statistical Methods for Psychologists. Boston: PWS Publishers.
Humason, G.L. (1972) Animal Tissue Techniques, 3rd ed. San Francisco: W.H. Freeman \& Co.

Johns, P.R. (1982) The formation of photoreceptors in the growing retinas of larval and adult goldfish. J. Neurosci. 2:179-198.

Johns, P.R., and S.S. Easter (1977) Growth of the adult goldfish eye: II. Increase in retinal cell number. J. Comp. Neurol. 176:331-342.

Johns, P.R., and R.D. Fernald (1981) Genesis of rods in teleost fish retina Nature 293:141-142.

Johns, P.R., and J.W. Holcombe (1982) Ontogeny of rods and cones in larval goldfish. Invest. Ophthalmol. Vis. Sci. [Suppl.] 21:204.

Kajishima, T. (1960) The normal developmental stages of the goldfish, Carassius auratus. Jpn. J. Icthyol. 8:20-28

Kinney, M.S., and S.K. Fisher (1978) The photoreceptors and pigment epithelium of the larval Xenopus retina: Morphogenesis and outer segment renewal. Proc. R. Soc. Lond. [Biol.] 201:149-167

Langford, L.A., and R.E. Coggeshall (1981) Branching of sensory axons in the peripheral nerve of the rat. J. Comp. Neurol 203:745-750.

Lyall, A.H. (1957a) The growth of the trout retina. Q. J. Microsc. Sci. 98:101 110.

Lyall, A.H. (1957b) Cone arrangements in teleost retinat. Q. J. Microsc. Sci. 98:189-201.

Marc, R.E., and H.G. Sperling (1976) Color receptor identities of goldfish cones. Science 191:487-488.

McArdle, C.B., J.E. Dowling, and R.J. Masland (1977) Development of outer segments and synapses in the rabbit retina. J. Comp. Neurol. 175:253274.

Müller, H. (1952) Bau und Wachstum der Netzhaut des Guppy (Lebistes reticulatus). Zool. Jb. 63:275-324

Nilsson, S.E.G. (1964) Receptor cell outer segment development and ultra structure of the disc membranes in the retina of the tadpole (Rana pipiens). J. Ultrastruct. Res, 11:581-620.

O'Day, W.T., and R.W. Young (1979) The effects of prolonged exposure to cold on visual cells of the goldfish. Exp. Eye Res. 28:167-187.

Olney, J.W. (1968) An electron microscopic study of synapse formation receptor outer segment development, and other aspects of developing mouse retina. Invest. Ophthalmol. 7:250-268.

Raymond, P.A., and P.K. Rivlin (1984) Three-dimensional reconstruction from serial electron microscopic autoradiographs of dividing rod precursors in goldfish retina. In G.W. Bailey (ed): Proceedings of the $42 \mathrm{nd}$ Annual Meeting of the Electron Microscopy Society of America. San Francisco: San Francisco Press, pp. 724-725.

Rogers, A.W. (1979) Techniques of Autoradiography, 3rd ed. New York Elsevier/North Holland.

Rugh, R. (1962) Experimental Embryology Techniques and Procedures. Min neapolis: Burgess Pub. Co.

Sandy, J.M., and J.H.S. Blaxter (1980) A study of retinal development in larval herring and sole. J. Mar. Biol. Assoc. UK 60:59-71.

Smelser, G.K., V. Ozanics, M. Rayborn, and D. Sagun (1974) Retinal synap togenesis in the primate. Invest. Ophthamol. 13:340-361.

Spira, A.W. (1975) In utero development and maturation of the retina of a non-primate mammal: A light and electron microscopic study of the guinea pig. Anat. Embryol. 146:279-300.

Stell, W.K. (1967) The structure and relationships of horizontal cells and photoreceptor-bipolar synaptic complexes in goldfish retina. Am. J. Anat. 121:401-424

Stell, W.K., and D.O. Lightfoot (1975) Color-specific interconnections of cones and horizontal cells in the retina of the goldfish. J. Comp. Neurol. 159:473-502.

Stell, W.K., and F.I. Hárosi (1976) Cone structure and visual pigment con tent in the retina of the goldfish. Vision Res. 16:647-657

Stell, W.K and J.-H. Kock (1984) Structure, development and visual activ ity in the goldfish retina. In J.B. Sheffield and S.R. Hilfer (eds): Molec ular and Cellular Basis of Visual Acuity: Seventh Symposium on Ocular and Visual Development. New York: Springer-Verlag, pp. 79-105.

Szamier, R.B., and H. Ripps (1983) The visual cells of the skate retina Structure, histochemistry and disc-shedding properties. J. Comp. Neu rol. 215:51-62

Wagner, H.-J. (1974) Development of the retina of Nannacara anomala (Regan) (Cichlidae, Teleostei) with special reference to regional variations of differentiation. Z. Morphol. Tiere 79:113-131.

Walts, G.L. (1967) The Vertebrate Eye and its Adaptive Radiation. New York: Hafner Publ. Co.

Young, R.W. (1969) A difference between rods and cones in the renewal of outer segment protein. Invest. Ophthalmol. 8:222-231. 